\title{
Heparin versus danaparoid in off-pump coronary bypass grafting: Results of a prospective randomized clinical trial
}

\author{
Michel Carrier, MD \\ Danielle Robitaille, $M D^{b}$ \\ Louis P. Perrault, MD, PhD \\ Michel Pellerin, MD \\ Pierre Pagé, $M D^{\mathrm{a}}$ \\ Raymond Cartier, $\mathrm{MD}^{\mathrm{a}}$ \\ Denis Bouchard, MDa
}

From the Department of Surgery a and the Laboratory of Hematology, ${ }^{\mathrm{b}}$ Montreal Heart Institute and University of Montreal, Montreal, Quebec, Canada.

There was no relationship of one of the authors with a for-profit organization related to the present study.

Received for publication Jan 18, 2002; revisions requested April 10, 2002; revisions received April 26, 2002; accepted for publication June 2002.

Address for reprints: Michel Carrier, MD, Research Center, Montreal Heart Institute, 5000 Bélanger St East, Montreal, Quebec, Canada H1T (E-mail: carrier@icm. umontreal.ca).

J Thorac Cardiovasc Surg 2003;125:325-9

Copyright $(\odot 2003$ by The American Association for Thoracic Surgery

$0022-5223 / 2003 \$ 30.00+0$

doi: $10.1067 / \mathrm{mtc} .2003 .103$
Objective: The incidence of heparin-induced thrombocytopenia is increasing, and the thrombin inhibitor danaparoid could be a useful alternative. The objective of the present study was to compare danaparoid and heparin in patients undergoing off-pump coronary artery bypass grafting.

Methods: In a prospective, randomized, double-blind clinical trial comparing heparin (bolus of $1 \mathrm{mg} / \mathrm{kg}$ ) with danaparoid (bolus of $40 \mathrm{U} / \mathrm{kg}$ ), 71 patients underwent off-pump coronary artery bypass grafting with one of the study drugs. The amount of blood lost, the number of homologous blood products transfused, the troponin $\mathrm{T}$ levels, and the amount of anti-Xa activity were monitored.

Results: Thirty-four patients underwent $2.6 \pm 0.7$ bypasses with danaparoid, and 37 patients underwent $2.5 \pm 0.9$ grafts with heparin $(P=.8)$. Postoperative blood losses averaged $1394 \pm 1033 \mathrm{~mL}$ in patients receiving danaparoid and $1130 \pm 868$ $\mathrm{mL}$ in patients receiving heparin $(P=.2)$. The number of homologous blood products transfused averaged $3.6 \pm 7$ units in patients receiving danaparoid and $1.9 \pm 4.4$ units in patients receiving heparin $(P=.2)$. The number of patients requiring homologous blood transfusion was higher in patients receiving danaparoid $(18 / 34[53 \%])$ than in patients receiving heparin (10/37 [27\%], $P=.03)$. Serum anti-Xa activity averaged $1.6 \pm 0.6 \mathrm{U} / \mathrm{mL}$ in patients receiving danaparoid and $1.9 \pm 0.8 \mathrm{U} / \mathrm{mL}$ in patients receiving heparin 30 minutes after injection of the drugs $(P=.1)$ and $0.3 \pm 0.1$ and $0.04 \pm 0.08 \mathrm{U} / \mathrm{mL}$, respectively, 12 hours after coronary artery bypass grafting $(P=.001)$. Troponin serum levels were similar 48 hours after coronary artery bypass grafting $(0.5 \pm 0.6$ and $0.4 \pm 0.6 \mu \mathrm{g} / \mathrm{L}$, respectively).

Conclusion: Although off-pump coronary artery bypass grafting with danaparoid versus heparin increases the number of patients exposed to homologous blood transfusion (relative risk, 2; 95\% confidence limits, 1-4), off-pump coronary artery bypass grafting with danaparoid is a valuable alternative to heparin in patients with thrombocytopenia requiring surgical intervention.

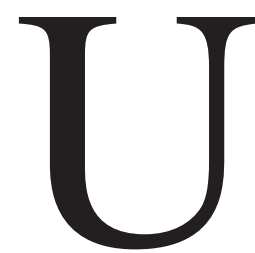

nfractionated heparin is the standard anticoagulant in patients undergoing cardiopulmonary bypass (CPB). ${ }^{1}$ There are very few contraindications to the use of standard heparin, but heparininduced thrombocytopenia (HIT) is emerging as a significant complication. ${ }^{2}$ Although the incidence of this immune-mediated reaction to heparin appears low (between $1 \%$ and $2 \%$ ), the risk of thrombotic complications is well documented. ${ }^{3,4}$ Because most patients with unstable angina are administered intravenous heparin for the medical management of the condition, heparin-associated thrombocytopenia is frequently recognized before 
coronary bypass grafting surgery. Thus, several investigators have attempted to find alternatives to heparin in patients undergoing CPB. ${ }^{5,6}$

Danaparoid, a heparin-free mixture of glycosaminoglycans derived from the porcine intestinal mucosa, was suggested as an alternative to heparin in patients with HIT who underwent CPB. ${ }^{2}$ Danaparoid offers several advantages, such as a more specific inhibition at the Xa level compared with that produced with heparin and a lower cross-reactivity with the heparin-induced antibodies compared with that seen with low-molecular-weight heparins. Also, danaparoid has several disadvantages, such as the lack of a direct neutralizing agent and a long half-life of 25 hours. $^{7}$ Moreover, the use of danaparoid and of all alternative agents to heparin during CPB has been associated with serious postoperative bleeding complications. ${ }^{1,2}$

Although off-pump coronary artery bypass grafting (OPCABG) is widely performed in several institutions, the exact role and indications for the procedure remain undefined. ${ }^{8}$ Several authors have suggested that OPCABG could especially benefit patients at high risk of complications related to the use of the $\mathrm{CPB}$ system. ${ }^{9}$ OPCABG in patients with HIT could be an alternative to conventional coronary artery bypass grafting (CABG) with $\mathrm{CPB}$ if a valuable alternative to heparin could be used. Thus, we suggest that a low-dose administration of danaparoid in OPCABG is a valuable alternative to the use of heparin.

We therefore undertook a double-blind, prospective, randomized clinical trial to compare the anticoagulants danaparoid and heparin in patients undergoing OPCABG surgery. The primary objective of the study was to compare blood loss in patients undergoing OPCABG with standard heparin versus danaparoid. The secondary aim of the study was to determine the effect of the 2 drugs on the percentage of patients requiring any type of homologous blood product transfusions and the number of blood product units transfused per patient after surgical intervention. Finally, we looked to compare the safety of the 2 drugs by measuring antithrombotic effects and overall myocardial ischemic damage.

\section{Methods}

\section{Study Population}

From November 1999 to June 2001, patients admitted to our institution for CABG who appeared to be good candidates for off-pump surgery were offered the option to participate in the study. Written informed consent was obtained from all recruited patients after explanation of the potential risks and benefits of the study. The study was approved and monitored by the Ethics Committee of the Research Center of the Montreal Heart Institute. Exclusion criteria consisted of preoperative known coagulopathy, patients unable to give an informed consent, and patients with contraindications to OPCABG (ie, small coronary arteries, intramyocardial arteries, associated valve procedures, and hemodynamic unstablility).

\section{Operative Procedure}

Perioperative management was standardized in the 2 groups. OPCABG was performed with the use of commercially available myocardial stabilizers and previously reported surgical techniques. ${ }^{10,11}$ In the control group heparin was administered as a $1 \mathrm{mg} / \mathrm{kg}$ bolus and was reversed with a $1 \mathrm{mg} / \mathrm{kg}$ dose of protamine sulfate after CABG. In the treated group danaparoid was administered as a $40 \mathrm{U} / \mathrm{kg}$ bolus, and a placebo was injected after CABG. Heparin, danaparoid, protamine, and the placebo injections were prepared by the hospital pharmacists and were administered blind to all physicians.

In both groups mediastinal drainage was achieved with a commercially available autotransfusion system.

\section{Postoperative Transfusion}

Postoperative homologous blood products were administered according to the following criteria during the study period. The threshold for homologous red blood cell transfusion was $80 \mathrm{~g} / \mathrm{L}$. Clotting factors were administered for persistent bleeding only after discussion with our hematology consultant, who had access to the code of randomization if needed. Four units of fresh frozen plasma were given for persistent moderate $(100-300 \mathrm{~mL} / \mathrm{h})$ or severe $(300 \mathrm{~mL} / \mathrm{h}$ for 2 hours) bleeding with an international normalized ratio of greater than 1.8. For bleeding patients with platelet counts of less than $80 \times 10^{9} / \mathrm{L}, 8$ units of platelets were transfused, and 8 units of cryoprecipitate were administered for fibrinogen levels of less than $1.0 \mathrm{~g} / \mathrm{L}$.

\section{Safety Measurement of Anticoagulant Activity and Myocardial Damage}

Serum cardiac troponin T levels were measured 24 and 48 hours after CABG to determine the overall ischemic damage in both groups. ${ }^{12}$ Anti-Xa activity was also measured in the 2 groups of patients 30 minutes and 12 hours after administration of the study drugs to determine antithrombotic activity. The laboratory was unblinded to permit dosage of anti-Xa level appropriate with the anticoagulant used. Because danaparoid and unfractionated heparin have their own specific anti-Xa activity, heparin and danaparoid were used independently for calibration of standard curves. The biologic activity of both anticoagulants resides in their ability to accelerate the inhibitory effect of antithrombin on coagulation proteases. We used the IL test heparin kit (Instrumentation Laboratory, Lexington, Mass), which is based on a synthetic chromogenic substrate and on factor $\mathrm{Xa}$ inactivation. Anti-Xa level in patients is measured on ACL 3000 (Beckman Coulter, Inc) in 2 stages. First, to obtain a constant concentration of antithrombin III, purified antithrombin III is added to the tested plasma. Factor Xa is then added to the tested plasma in excess and is neutralized by heparin-antithrombin III of danaparoid-antithrombin III. Second, residual factor $\mathrm{Xa}$ is then quantified with a synthetic chromogenic substrate and is inversely proportional to the anti-Xa activity in the sample.

\section{Statistical Analysis}

The study was designed to demonstrate equivalence in the postoperative blood loss values on the basis of our earlier experience with OPCABG. ${ }^{10,13}$ It was estimated that 120 patients had to be randomized into 2 groups. Patients were randomized to the heparin group or the danaparoid group by use of a table of random digits by 
blocks of 4 . The study was stopped for a preliminary analysis of the primary and secondary end points after enrolling 71 patients because it appeared clinically that some patients were administered a greater number of homologous blood transfusions compared with data from our earlier experience with patients undergoing OPCABG. ${ }^{10,13}$

Blood tests and different measurements of standardized data were done according to a strict protocol identical in both groups. All data were prospectively collected from the chart of every enrolled patient by 3 research assistants. For the purpose of the study, the term transfusion refers to any administration of homologous blood products, including homologous packed red blood cell units, platelets, fresh frozen plasma, and cryoprecipitate units.

Data are expressed as means, SDs, and 95\% confidence limits (CLs) when specified. Statistical comparisons were done with the unpaired Student $t$ test, the $\chi^{2}$ test, and the Fischer exact test. Relative risk and the $95 \% \mathrm{CL}$ was calculated to study the exposure of patients of the 2 groups to homologous blood transfusions. Univariate and multiple logistic regression analyses were performed to identify the relationship between the need for homologous blood transfusion and several clinical variables in the 2 groups. Data analysis was performed with the Number Cruncher Statistical System 2001 (NCSS Statistical Software).

\section{Results}

Patients in the danaparoid and heparin groups were similar for all clinical and demographic parameters (Table 1). Most patients had triple-vessel coronary artery disease, and $38 \%$ to $56 \%$ of patients were administered intravenous heparin until the time of the operation because of unstable angina. Between $40 \%$ and $50 \%$ of patients were also administered aspirin before the operation (Table 1).

The numbers of CABGs averaged $2.6 \pm 0.7$ and $2.5 \pm$ 0.9 in patients receiving danaparoid and heparin, respectively $(P=.8$, Table 2$)$. The duration of the operation and the intraoperative blood losses were similar in the 2 groups. There was no conversion to CPB in either group.

Although the hemoglobin levels and platelet counts were similar between the 2 groups before the operation, the hemoglobin level was significantly lower in patients with danaparoid during the first day after the operation compared with that in patients receiving heparin (Table 3 ). The activated clotting time during the operation was also significantly lower among patients who were administered danaparoid during CABG. Initially, the measure of anti-Xa activity was similar in the 2 groups during the operation, but the anti-Xa activity was higher in patients receiving danaparoid compared with in patients receiving heparin 12 hours after the operation (Table 3).

The postoperative amount of blood drained from the mediastinum averaged $1394 \pm 1033 \mathrm{~mL}$ (95\% CL, 1034$1755 \mathrm{~mL}$ ) in patients receiving danaparoid compared with $1130 \pm 868 \mathrm{~mL}(95 \% \mathrm{CL}, 836-1424 \mathrm{~mL})$ in patients receiving heparin $(P=.2)$. Although the mean number of homologous blood products transfused per patient was similar in the 2 groups, $53 \%$ of the patients receiving danap-
TABLE 1. Clinical and angiographic characteristics of patients

\begin{tabular}{lccc}
\hline No. of patients & $\begin{array}{c}\text { Danaparoid } \\
(\mathbf{n}=\mathbf{3 4})\end{array}$ & $\begin{array}{c}\text { Heparin } \\
(\mathbf{n}=\mathbf{3 7})\end{array}$ & $\boldsymbol{P}$ value \\
\hline Age (y) & $68 \pm 9$ & $65 \pm 10$ & .3 \\
Men/women & $26 / 8$ & $31 / 6$ & .4 \\
Stable/unstable angina & $22 / 12$ & $18 / 19$ & .2 \\
Recent MI & 4 & 7 & .4 \\
Left main stenosis & 5 & 9 & .4 \\
Single-vessel disease & 3 & 2 & .7 \\
Two-vessel disease & 10 & 14 & .6 \\
Three-vessel disease & 21 & 21 & .8 \\
LV dysfunction & 4 & 5 & .9 \\
Preoperative intravenous heparin & 19 & 14 & .2 \\
Preoperative aspirin (within 7 d) & 17 & 15 & .5 \\
\hline
\end{tabular}

$M I$, Myocardial infarction; $L V$, left ventricular.

aroid were administered homologous blood products compared with $27 \%$ of the patients receiving heparin, which was a significant difference $(P=.03$, Table 4$)$.

Serum troponin T levels averaged $0.5 \pm 0.6$ and $0.5 \pm 0.6$ $\mu \mathrm{g} / \mathrm{L} 24$ and 48 hours after OPCABG in patients receiving danaparoid compared with $0.5 \pm 1 \mu \mathrm{g} / \mathrm{L}(P=.8)$ and $0.4 \pm$ $0.6 \mu \mathrm{g} / \mathrm{L}(P=.4)$ in patients receiving heparin, respectively. There was one patient with a perioperative myocardial infarction in each group (1/34 [3\%] and 1/37 [3\%], respectively). One patient with severe Parkinson disease before the operation underwent OPCABG with danaparoid and showed generalized convulsions and coma for a few days after the operation but recovered completely thereafter. One patient in the danaparoid group (1/34 [3\%]) required surgical re-exploration for excessive mediastinal bleeding after CABG. Length of stay in the intensive care unit and in the hospital averaged $2 \pm 1$ and $5 \pm$ 1 days, respectively, in patients receiving danaparoid and $2 \pm$ 3 days $(P=.8)$ and $6 \pm 3$ days $(P=.6)$, respectively, in patients receiving heparin. There was no death in either group.

Univariate analyses performed to study risk factors related with blood transfusions in OPCABG showed that women with lower hemoglobin levels before CABG and the use of danaparoid were associated with higher transfusion requirements after the operation (Table 5). In a multivariable analysis the use of danaparoid remained the only risk factor significantly related to the need for blood transfusion after OPCABG (Table 6).

\section{Discussion}

The present double-blind, randomized clinical trial comparing the anticoagulants danaparoid and heparin in OPCABG demonstrated a $26 \%$ increase (relative risk, 2; 95\% CL, 1-4) in the percentage of patients exposed to homologous blood products with the use of danaparoid. Although blood losses were similar during the operation, postoperative mediastinal blood drainage was higher in patients receiving danaparoid. The measure of anti-Xa activity remained high 12 hours after $\mathrm{CABG}$ in patients receiving danaparoid compared with 
TABLE 2. Intraoperative characteristics

\begin{tabular}{|c|c|c|c|}
\hline & $\begin{array}{c}\text { Danaparoid } \\
(\mathrm{n}=34)\end{array}$ & $\begin{array}{l}\text { Heparin } \\
(\mathrm{n}=37)\end{array}$ & $P$ value \\
\hline No. of grafts per patient & $2.6 \pm 0.7$ & $2.5 \pm 0.9$ & .8 \\
\hline Duration of the operation (min) & $146 \pm 36$ & $140 \pm 41$ & .5 \\
\hline Conversion to $\mathrm{CPB}$ & 0 & 0 & \\
\hline Intraoperative blood loss (mL) & $485 \pm 346$ & $478 \pm 282$ & .9 \\
\hline \multicolumn{4}{|l|}{ Cardiac index (L-min-m $\left.{ }^{-2}\right)$} \\
\hline Before the operation & $2.6 \pm 0.6$ & $2.5 \pm 0.5$ & 6 \\
\hline After the operation & $2.7 \pm 0.7$ & $2.6 \pm 0.6$ & 6 \\
\hline
\end{tabular}

TABLE 3. Coagulation and blood profile

\begin{tabular}{|c|c|c|c|}
\hline & $\begin{array}{c}\text { Danaparoid } \\
(\mathrm{n}=34)\end{array}$ & $\begin{array}{l}\text { Heparin } \\
(\mathrm{n}=37)\end{array}$ & $P$ value \\
\hline Hemoglobin before the operation $(\mathrm{g} / \mathrm{L})$ & $129 \pm 15$ & $134 \pm 18$ & .2 \\
\hline Hemoglobin POD 1 (g/L) & $90 \pm 12$ & $97 \pm 13$ & .02 \\
\hline Platelets before the operation $\left(\times 10^{9} / \mathrm{L}\right)$ & $240 \pm 60$ & $238 \pm 84$ & .9 \\
\hline Platelets POD $1\left(\times 10^{9} / \mathrm{L}\right)$ & $161 \pm 53$ & $167 \pm 57$ & .7 \\
\hline ACT during the operation (s) & $223 \pm 103$ & $394 \pm 150$ & .001 \\
\hline \multicolumn{4}{|l|}{ Anti-Xa activity (U/mL) } \\
\hline 30 min after intravenous injection & $1.6 \pm 0.6$ & $1.9 \pm 0.8$ & .1 \\
\hline $12 \mathrm{~h}$ after intravenous injection & $0.3 \pm 0.1$ & $0.04 \pm 0.08$ & .001 \\
\hline \multicolumn{4}{|l|}{ Troponin T serum levels $(\mu \mathrm{g} / \mathrm{L})$} \\
\hline $24 \mathrm{~h}$ after $\mathrm{CABG}$ & $0.5 \pm 0.6$ & $0.5 \pm 1$ & .8 \\
\hline $48 \mathrm{~h}$ after $\mathrm{CABG}$ & $0.5 \pm 0.6$ & $0.4 \pm 0.6$ & .4 \\
\hline
\end{tabular}

$P O D$, Postoperative day; $A C T$, activated clotting time.

TABLE 4. Exposure to homologous blood products

\begin{tabular}{lllc}
\hline & $\begin{array}{c}\text { Danaparoid } \\
(\mathbf{n}=\mathbf{3 4})\end{array}$ & $\begin{array}{c}\text { Heparin } \\
(\mathbf{n}=\mathbf{3 7 )}\end{array}$ & $\boldsymbol{P}$ value \\
\hline Packed red blood cells & $1.3 \pm 1.7$ & $0.7 \pm 1.4$ & .1 \\
Platelets & $1.1 \pm 2.3$ & $0.9 \pm 2.6$ & .8 \\
Fresh frozen plasma & $0.8 \pm 2$ & $0.3 \pm 1$ & .2 \\
Cryoprecipitate & $0.5 \pm 2.7$ & 0 & .3 \\
Total & $3.6 \pm 7$ & $1.9 \pm 4$ & .2 \\
Patients transfused (\%) & $18(53 \%)$ & $10(27 \%)$ & .03 \\
\hline
\end{tabular}

TABLE 5. Univariate analysis of the determinants of transfusion requirement for all patients

\begin{tabular}{lccc}
\hline Characteristics & Odds ratio & 95\% CL & $\boldsymbol{P}$ value \\
\hline Sex (women) & 5.42 & $1.49-19.62$ & .01 \\
Hemoglobin level (g/L) & 0.965 & $0.949-0.984$ & .035 \\
Use of danaparoid & 3.04 & $1.13-8.17$ & .027 \\
\hline
\end{tabular}

almost no anti-Xa activity in those receiving heparin, indicating that, in the latter patients, the protamine was effective in neutralizing the effect of heparin as opposed to the placebo used in the danaparoid group. The persistence of anti-Xa activity with danaparoid explains the higher blood losses and the higher requirement for homologous blood transfusions in this group.
TABLE 6. Multivariable analysis of the determinants of transfusion requirement for all patients

\begin{tabular}{lccc}
\hline Characteristics & Odds ratio & 95\% CL & $P$ value \\
\hline Sex (women) & 3.62 & $0.77-17.1$ & .1 \\
Hemoglobin level (g/L) & 0.98 & $0.96-1.03$ & .4 \\
Use of danaparoid & 3.71 & $1.22-11.25$ & .02 \\
\hline
\end{tabular}

Although mediastinal blood loss and the need for transfusions were higher in patients with danaparoid compared with in those with heparin (53\% vs $27 \%$, respectively), we have showed, in a recent study on reinfusion of mediastinal blood after on-pump cardiac surgery, that $55 \%$ of the reinfused patients were administered homologous blood products after the operation. ${ }^{14}$ Thus, our group of off-pump patients receiving a low dose of the anticoagulant danaparoid showed similar blood losses and received a similar number of homologous blood products after the operation when compared with a group of on-pump patients receiving heparin. ${ }^{14}$

Several authors have suggested that OPCABG with the use of heparin results in a decrease in the use of homologous blood products when compared with that seen in patients undergoing operations with the CPB system. ${ }^{8,9}$ Results of the present study corroborate these reports. Only 27\% of patients who underwent OPCABG with heparin required 
homologous blood products after the operation, the lowest rate that our group has reported in recent years. ${ }^{14}$

Increased activated clotting time and anti-Xa activity values during surgical intervention in the 2 groups suggest that the antithrombotic effect of the 2 drugs was adequate during the operation. The higher blood losses and transfusion requirements in patients receiving danaparoid appear related to the prolonged and nonreversible effect of the drug. However, serum troponin T levels were similar in the 2 groups after $\mathrm{CABG}$, suggesting that the overall ischemic damage was identical in the 2 groups.

Although the present results show a significant increase in the requirement of blood transfusions in patients who undergo OPCABG with danaparoid, we suggest that this approach is a valuable alternative to unfractionated heparin and CPB in patients with serious contraindications to the use of heparin. Bauer and colleagues ${ }^{15}$ reported that one fifth of patients undergoing CPB surgery have heparininduced platelet antibodies detectable before the procedure as result of prior exposure to heparin, and several more had antibodies after the operation. Heparin is far more immunogenic than has been appreciated. ${ }^{16}$ Walls and coworkers ${ }^{17}$ and Singer and associates ${ }^{18}$ reported that unrecognized HIT in patients undergoing CPB results in serious bleeding and thromboembolic complications after the operation.

Other anticoagulants have been used as alternatives to heparin in patients undergoing $\mathrm{CPB}$, but danaparoid is the drug most often used in clinical practice. ${ }^{1,2}$ Because high doses of danaparoid in patients with CPB appears to result in bleeding complications after the operation, we chose a lower dose of danaparoid and an off-pump approach for CABG. ${ }^{1}$ The peak anti-Xa activities measured in our patients with danaparoid are similar to levels reported by Frederiksen ${ }^{1}$ in reviewing the surgical literature of patients undergoing operations with danaparoid. Yet mediastinal drainage and transfusion requirements remained higher with the use of danaparoid compared with heparin because of the long half-life and the absence of a specific antidote to the former drug.

Follis and Schmidt ${ }^{2}$ suggested that the simplest strategy in patients with heparin-induced antibodies is to postpone the operation for 6 to 8 weeks and monitor the level of antibodies. Some reports suggest that it is safe to proceed with heparin if there are no antibodies. We suggest that OPCABG with danaparoid is a valuable alternative in patients in whom the wait appears to increase the surgical risk.

In conclusion, patients who underwent OPCABG with low-dose danaparoid were at greater risk of exposure to homologous blood products and required a greater number of transfusions compared with patients who underwent offpump surgery with heparin. Antithrombotic activity was identical, and ischemic damage after CABG was also similar between drugs. Although a larger percentage of patients receiving danaparoid required blood transfusions, the per- centage of patients being transfused with danaparoid OPCABG is similar to numbers seen in previous reports with $\mathrm{CPB}$ and heparin. Thus, OPCABG with danaparoid is a safe alternative in patients with HIT requiring CABG.

The present study suggest that OPCABG offers new approaches and valuable alternatives to patients who present preoperative risk factors associated with high morbidity when the operation is performed by using a more conventional approach with CPB. We suggest that HIT in patients who need immediate $\mathrm{CABG}$ is an indication for the use of OPCABG techniques and the anticoagulant danaparoid.

\section{References}

1. Frederiksen JW. Cardiopulmonary bypass in humans: bypassing unfractioned heparin. Ann Thorac Surg. 2000;70:1434-43.

2. Follis F, Schmidt CA. Cardiopulmonary bypass in patients with heparin-induced thrombocytopenia and thrombosis. Ann Thorac Surg. 2000;70:2173-81.

3. Schmitt BP, Adelman B. Heparin-associated thrombocytopenia: a critical review and pooled analysis. Am J Med Sci. 1993;305:208-15.

4. Warkentin TE, Kelton JG. A 14-year study of heparin-induced thrombocytopenia. Am J Med. 1996;101:502-7.

5. Doherty DC, Ortel TL, De Bruijn N, Greenberg CS, Van Trigt P. Heparin-free cardiopulmonary bypass: first reported use of heparinoid (Org 10172) to provide anticoagulation for cardiopulmonary bypass. Anesthesiology. 1990:73:562-5.

6. Koster A, Pasic M, Bauer M, Kuppe H, Hertzer R. Hirudin as anticoagulant for cardiopulmonary bypass: importance of preoperative renal function. Ann Thorac Surg. 2000;69:37-41.

7. Wilde MI, Markham A. Danaparoid. Review of its pharmacology and clinical use in the management of heparin-induced thrombocytopenia. Drugs. 1997;54:903-24.

8. Kshettry VR, Flavin TF, Emery RW, Nicoloff DM, Arom KV, Petersen RJ. Does multivessel off-pump coronary artery bypass reduces postoperative morbidity. Ann Thorac Surg. 2000;69:1725-30.

9. Stamou SC, Corson PJ. Coronary revascularization without cardiopulmonary bypass in high-risk patients: a route to the future. Ann Thorac Surg. 2001;71:1056-61.

10. Cartier R. Systematic off-pump coronary artery revascularization: experience of 275 cases. Ann Thorac Surg. 1999;68:1494-7.

11. Perrault LP, Nickner C, Desjardins N, Carrier M. Effects of coronary endothelial function of the Cohn stabilizer for beating heart bypass operations. Ann Thorac Surg. 2000;70:1111-4.

12. Carrier M, Pellerin M, Perrault LP, Solymoss BC, Pelletier LC. Troponin levels in patients with myocardial infarction after coronary artery bypass grafting. Ann Thorac Surg. 2000;69:435-40.

13. Dagenais F, Perrault LP, Cartier R, Searle N, Pagé P, Pellerin M, et al. Beating heart coronary artery bypass grafting: technical aspects and results in 200 patients. Can J Cardiol. 1999;15:867-72.

14. Martin J, Robitaille D, Perrault LP, Pellerin M, Pagé P, Searle N, et al. Reinfusion of mediastinal blood after heart surgery. J Thorac Cardiovasc Surg. 2000;120:499-504.

15. Bauer TL, Arepally G, Konkle BA, Mestichelli B, Shapiro SS, Cines DB, et al. Prevalence of heparin-associated antibodies without thrombosis in patients undergoing cardiopulmonary bypass surgery. Circulation. 1997;95:1242-6.

16. Konkle BA, Bauer TL, Arepally G, Cines DB, Poncz M, McNulty S, et al. Heparin-induced thrombocytopenia: bovine versus porcine heparin in cardiopulmonary bypass surgery. Ann Thorac Surg. 2001;71:1920-4.

17. Walls JT, Curtis JJ, Silver D, Boley TM, Schmaltz RA, Nawarawong W. Heparin-induced thrombocytopenia in open heart surgical patients: sequela of late recognition. Ann Thorac Surg. 1992;53:787-91.

18. Singer RL, Mannion JD, Bauer TL, Armenti FR, Edie RN. Complications from heparin-induced thrombocytopenia in patients undergoing cardiopulmonary bypass. Chest. 1993;104:1436-40. 